\title{
The Efficiency of Social Skills Training and the Fordys Cognitive- Behavioral Model of Joy in Incrased Happiness of Students
}

\author{
Elahe Beheshtian
}

M.A. in Clinical Psychology, Department of Psychological Sciences, Faculty of Humanities, Neyshabur Branch, Islamic Azad University, Neyshabur, Iran

\author{
Dr. Hassan Toozandehjani* \\ Assistant Professor of psychology, Department of Psychological Sciences, Faculty of Humanities, Neyshabur Branch, \\ Islamic Azad University, Neyshabur, Iran \\ *Corresponding Author Email: H.Toozandehjani@ymail.com \\ Elham Ghajari
}

Young Researchers and Elite club, Neyshabur Branch, Islamic Azad university, Neyshabur, Iran

\author{
Doi:10.5901/mjss.2016.v7n3s3p119
}

\section{Abstract}

This research were done in order to investige the efficacy of cognitive-behavioral instruction of social skills in comparison with Fordyce's trainings in increased happiness of secondary school in Neyshabour. Therefore, 120 students was selected. Atfirst, thejoy level of students was assessed by Oxford's Happiness test and their anxiety and depression levels were measured by Beck's Depression test and Schpilbergere's Trait-state Anxiety questionnaire. Then four experiment faced with independent variables by seven to ten sessions. Onceagain, at the end of the training period, all groups were assessed by the abovementioned tests. Also, follow-up assays were conducted one month after the end of training. The results were analyzed by one- and two-factor variance analysis tests as well as the Shefe's ad-hoc test. The study results indicated that trial and control groups have significant difference in respect of happiness rate. The results of Shefe's ad-hoc test showed that cognitivebehavioral instruction of social skills is more efficient than Fordyce Trainings. In respect of anxiety level of students, there was no significant effect of cognitive-behavioral instruction of social skills and Fordyce trainings on increased happiness of students. But the students who had a higher level of depression were more affected by these trainings. Also, it was shown that age and education variables had no effect on effectiveness of trainings.

Keywords: Social Skills Training, Fordys Cognitive- Behavioral, Happiness

\section{Introduction}

The rapid changes of social and cultural conditions, a higher level of anxiety, depression, lacking of self-confidence, discouragement about the future, truancy or leaving home, suicide and factors induceing immoral competitions across the society( especially in educating population), all explain the necessity of this study. Schools, as the most important place of the next generation attendance, must be a healthy and dynamic environment. So, the students' happiness and youthfulness is a current important topic under discussion (Buss, 2000).

The students' happiness depends on the existence of fascinating, pleased and enlivening climate in schools. But, most of the students complain about their schools being boring, tedious and without dynamism. So, greater effort to bring a juicy environment to schools helps us to cultivate a sense of worthiness in students (Aal-e-Yasin, 2001). Studies show that happiness, irrespective of the way of its gaining, could improve the people's physical health. Happy peoples have a higher sense of security, make decisions more easily, have a greater sense of cooperation and are more satisfied with their family (Myers 2002; Al-e-Yasin 2001).

Lyubomirsky (2001) refers to the role of personal factors in the students' happiness. He believes that positive attitude must be raised in peoples (especially students), because if they have a positive attitude, they will be able to solve problems that may have a side effect on their life more easily. According to Ryan \&Deci (2000), the people's evaluation of their life and their personal senses helps them to become happy. 
A research conducted by Buss (2000) shows that numerous factors contribute in pleasing a schools climate, including happy principal and teachers, the school's lively organization, clean and well- organized classrooms and their appropriate space for learning, and conducting exhilarating ceremonies. Thompson (2003) found that light and the window view have a positive effect of the students' learning. In his study, he showed those physical and mental effects of colors and their conformity are important in education centers and must be considered. In their research, Rittner\&Robbin (2002) found that color and light have an interesting influence on the students' learning and maintaining their lessons. Raterink (2002) demonstrated happiness as the main cause of the students' success. Phelan (1998) in his research on the organizational climate of school showed that the students attitude about school and their willingness to learning and being happy is greater in schools where teachers are more involved in the schools affairs.

Abedi et al. (2004) detected that there is a significant correlation between the students' level of happiness and the quality of their relationships with the principal, teachers, sport teacher and the consultant. Also, there was a significant correlation between students' happiness and the supportive, success- focused and collaborative styles of leading, but not with imperious style. Darikvandi (2002) found that psychological, physical, social, educational, economic and organizational factors influence on developing a sense of happiness in students.

Psychology of happiness measures the level of hopefulness, being lively and optimism (Barlow 2000). Happiness is the extent of a sense of a person about the good quality of his life. In other words, happiness means the extent to which an individual like his/her life (Veenhoven 1984). Lyubomirsky et al. (2005) believe that happiness is the experience of joy, cheerfulness and gladness and a sense of having a valuable, meaningful and good life. Argyle et al. (1989) defines happiness as composed of positive feelings, lacking of negative feelings and satisfaction of life.

Byrd et al. (2000) investigated relationships of four factors, respect for religious values and goals, fundamental needs, the life having a goal or aim and spiritual beliefs, with happiness. They found that religious commitment is a predicator of happiness. On the other hand, and based on research reports, it is shown that there is a great correlation between happiness and extroversion (Hills and Argayl 2001). Numerous studies have shown that different aspects of the peoples' character influence on their happiness. Gray (1982) reported that due to their brain structure, extrovert peoples are more sensitive to rewards and, so, are happier. But the neurotic ones are more responsive to punishment and, thus, feel a lower level of happiness.

It was indicated, in the study of Putnam et al, that peoples who have a higher level of social skills and communicate better are happier than rich persons who have no appropriate social relationships (quoted from Huppke 2001). Rose (2000) study suggests that, in comparison with human assets (education, income, status...), social assets are more effective in the public happiness. Intimate friends are a certain source of happiness. Investigating daily social activities of the university students, Berry \& Hans (1996) found that those students who have a high level of positive affection, present more social exposure and spend more time in social interactions. Also, they will participate in more fascinating and fun events. Lu \&Argayl (1991) in a study named as "happiness and cooperation" suggested that cooperation is an enlivening factor. The study results showed that students who take pleasure in group activities are happier.

Russ \&Miruski(1989) recognized that social support leads to decreased depression and anxiety. Philips (1967) conducted a study on the relation of socialization and happiness. Its results showed that socialization increase the level of happiness and decrease depression and anxiety. Studies have shown that mode, character, culture, social skills, the level of optimism and pessimism, being lively, social supports, and beliefs have a direct effect on the rate of happiness (Diener 2000). Results of a research by Myres (2000) and Peterson (2000) suggested that happiness can improve physical and mental health of an individual. People who are happier, have a higher sense of security, make decisions more easily and cooperate with others. Also, Vart (2001) states that self-esteem is an inseparable element of happiness and that depression decreases the level of joy and attention in people and limits their cognitive-behavioral pool.

Recently, some psychologists tried to present certain approaches to increase happiness. Of these are: Fordyce's Cognitive- Behavioral Model of Happiness Instruction, Lewinsohn\&Gotlib Instruction of Social Skills (1955), Beck's Cognitive Treatment (1991), Instruction of Interpersonal Relationships ( Buss 2000), and the Ways of Mode Induction (Argyle 1982)

As happiness is a communicable and internal phenomenon, extends ones relations with his/her environment, increase a sense of being lively and the students' interest to attend school and helps in their learning. So, to increase students' happiness rate, this study compares efficacy of two approaches (the Fordyce's Cognitive- behavioral model of happiness instruction, and Lewinsohn\&Gotlib Instruction of Social Skills).

Fordyce's model of happiness instruction:

This program is administered in two ways: instructional and consultative. In its consultative pattern, it tries to, while discovering ones thoughts and problems through cognitive and behavioral treatments, increase happiness rate in them 
(Fordyce 1982). Numerous researches have confirmed its efficacy in bringing up happiness (e.g. Fordyce 1983; Fordyce 1997; lyobomersky\&Lepper 1999; Abedi 2002; Abedi 2004).

Lewinsohn\&Gotlib Instruction of Social Skills:

Cognitive- behavioral pattern of social skills is a complex of cognitive and behavioral techniques to increase happiness. This includes expressing skills, spending leisure times efficiently, responsibility, altruism, cooperation skills, communication skills, self- regulation, daring, and etc. Different studies have demonstrated these factor effects on the increased joy of anxious and depressed patients and their families (e.g. Warger\& Rutherford 1996; Larson 2000; Kamls\& Kay 2002; Cheng \&Fumham 2002).

So, this study aims to investigate efficacy of Lewinsohn\&Gotlib cognitive- behavioral instruction of social skills in comparison with the Fordyce's cognitive- behavioral model of happiness on the increased happiness of third grade students of secondary schools. So, the following hypotheses are posed:

1. Cognitive- behavioral instruction of social skills and the Fordyce's cognitive- behavioral model of happiness influence on the increased happiness of students.

2. Cognitive- behavioral instruction of social skills and the Fordyce's cognitive- behavioral model of happiness influence on the decreased level of depression in students.

3. Cognitive- behavioral instruction of social skills and the Fordyce's cognitive- behavioral model of happiness influence on the decreased level of anxiety in students.

\section{Method}

This semi-empirical research ( including pre-test, post-test and follow up test along with control group) were done in order to investigate the efficacy of Fordyce's cognitive-behavioral instruction model in comparison with the social skills of Lewinsohn\&GotlibTherefore, a sample of 120 students was selected from the secondary school students (girls and boys) in multi-stage stratified random method and was divided into six groups of 20 , randomly. Then, one trial group of girls and one of boys received the Fordyce's cognitive-behavioral instructions and two others were instructed by Lewinsohn\&Gotlib cognitive- behavioral model of social skills. Four experiment groups exposed to happiness instruction programs during seven to ten sessions, each lasted for 90 minutes. Two control groups received no training. All subjects were assessed by pre-test (before experiment), post-test (after experiment), and one month after the end of experiment.

\subsection{Subjects (population, sample and sampling method)}

The study Population includes all third grade students (girl and boys) of secondary schools of Neyshabour during educational year of 2007-2008. Our sample composed of 120 girl and boy students selected by multistage stratified random method and divided into 6 groups ( 4 trial groups and 2 control groups), randomly.

\subsection{Instruments}

\subsubsection{Oxford Happiness Inventory:}

This inventory is composed by Argyle and Lu (1990) and includes 29 items. They reported reliability coefficient of 0.78 for their inventory. Also, a construct validity of 0.52 was reported for it through divergence method (correlation between Oxford happiness inventory and Beck's depression test) (Francis et al. 1998). Alipour et al. (2000) reported its 0.93 reliability coefficient by Kronback Alfa. Also, a reliability coefficient of 0.84 has obtained in this research.

\subsubsection{Beck's Depression Inventory:}

It can be said, daringly, that Beck's Depression Inventory is one of the most common self- report instruments for depression assessment. It was developed by Beck (1961) and revised by Robert Staker (1987). It includes 21 items and assesses different aspects of depression. Numerous studies have reported good validity and reliability for it (e.g. Beck et al. 1975). Correlation coefficient of pre-test scores, Beck's Depression Inventory and Hamilton's depression rating Scale as 0/66 was reported (Fetti 1991). Beck (1972) reported total items reliability of 0/31-0/68 and, measured by SpearmanBrawn Correlation, it was 0/93(Quoted from Toozandejani 1995). 


\subsubsection{Schpillberger's Anxiety State-trait Inventovry:}

It was developed by Schpillberger (1970) and is a self- report questionnaire that assesses state and trait anxiety, separately. Its reliability for state anxiety and trait anxiety are 0/91 and /90, respectively. Its total reliability of 0/94 has been reported (Mahram 1993; Marnat, quoted from Pasha Sharifi \& Nikkhu 1997).

\subsubsection{Administration of Fordyce's cognitive- behavioral model \& social skills}

Fordyce's Cognitive- behavioral model of happiness: These instructions are a collection of cognitive- behavioral techniques developed by Fordyce which are administered as following:

Engage and be active, do purposeful and cost-effective activities, spend more time on group works, organize and regulate daily affairs, reduce distresses, adjust expectations and desires, develop positive beliefs and optimism, attend to here and now, observe principles of character health, socialization, try to express your own identity, reduce your negative feelings, develop stable and enlivening relationships. This program was done in 10 session, each of 90 minutes.

During the first session, pre-test was administered, and subjects were introduced to cognitive- behavioral instructions of Fordyce. In the second session, techniques to express feelings were instructed. Third session involved introducing optimism skills. Forth session was devoted to instruction of techniques to raise intimacy. Increasing creativity and lowering expectations was the agenda of the fifth session and subjects were familiar with methods to increase their physical activities during sixth session. Seventh session was ended by instruction of social communications and techniques for programming and organization, being who you really are and living in here and now were presented in eight session. Ninth session was hold by instructions about lowering negative thoughts. Finally, to give priority to happiness and joy was the order of tenth session.

\subsubsection{Lewinsohn \& Gotlib cognitive- behavioral instruction of social skills:}

These instructions involve cognitive- behavioral skills to express feelings, making friends, discussion and negotiation, socialization, expressing one's own and skills, and effective communication skills. It was administered as following:

During the first session, the method of cognitive- behavioral instruction of social skills was introduced to subjects. Other next sessions were devoted to expressive skills and discussion (second session), making friends and effective communications (third session), spending leisure time more effectively and exercise (forth session), skills to express one's own (fifth session), introducing to skills of socialization (sixth session) and, finally, interpersonal and clear relationships (seventh session).

\subsection{Data Anlysis}

Data were analyzed by repeated- measures ANOVA. Means were compared by Sheffe's Ad-hoc Test.

\section{Findings}

Table 1: The results of repeated- measures ANOVA of difference between pre-test scores are summarized. Pre-test, post- test and follow-up test

\begin{tabular}{|c|c|c|c|c|c|c|}
\hline Origin of Changes & & $\begin{array}{c}\text { Square Roots } \\
\sum\end{array}$ & d.f. & Average of square roots & $\mathrm{F}$ & $P$ \\
\hline \multirow{4}{*}{ Between subjects } & $\operatorname{Sex} A$ & $116 / 36$ & 1 & $116 / 36$ & $0 / 59$ & 0.463 \\
\hline & Group S/A & $22582 / 86$ & 1 & $22582 / 86$ & $82 / 47$ & 0.000 \\
\hline & Sex $\times A B$ & $131 / 45$ & 2 & $65 / 73$ & $0 / 36$ & 0.752 \\
\hline & Error & $24347 / 74$ & 114 & $213 / 58$ & & \\
\hline \multirow{5}{*}{ Within subjects } & Trainings B & $428 / 31$ & 1 & $428 / 31$ & $9 / 02$ & 0.001 \\
\hline & Trainings $\times S / B$ & $264 / 96$ & 1 & $264 / 96$ & $5 / 83$ & 0.013 \\
\hline & Trainings $\times A B$ & $248 / 73$ & 1 & $248 / 73$ & $3 / 02$ & 0.094 \\
\hline & Trainings $\times$ sex $\times B / A$ & $723 / 23$ & 2 & $361 / 62$ & $7 / 82$ & 0.001 \\
\hline & Error & $5102 / 27$ & 114 & $44 / 76$ & & \\
\hline
\end{tabular}


As the results of repeated- measures two-factor ANOVA for difference of pre-test, post-test and follow-up test scores show, there is no significant difference between them in respect of $\operatorname{sex}(A)$ and interactions of sex and groups(AB) because measured $F(F=0 / 59,0 / 36)$ is lower than reference $F(F=4 / 54)$. But difference between groups (Factor $B)$ was significant, as the measured $F(F=7 / 82, P=0 / 001)$ was higher than reference $F(F=4 / 54)$ with a certain degree of freedom. So, in respect of level of happiness, there was a significant difference between trial and control groups. And it can be said, with \%95 confidence, that the author's claim that instructions influence on the students' level of happiness, is supported.

As there was a significant difference between groups, we used of Sheffe's ad hoc test to compare means. In this respect, the measures $t(t=7 / 32)$ was higher than reference $t(t=2 / 57)$. According to collected data and considering significant difference between groups, it was concluded that researcher's hypothesis on the significant difference between two methods of instruction is supported. In other words, the mean scores of group exposed to cognitive- behavioral instruction of social skills were lower than group members who were administered by the Fordyce's instructions. Therefore, instruction of social skills is more efficient than Fordyce instructions in raising students' happiness.

Table 2: a brief description of ANOVA results about anxiety

\begin{tabular}{|c|c|c|c|c|}
\hline Origin of changes & Square roots $\Sigma$ & d.f. & Mean & $F$ \\
\hline B.G. & $298 / 26$ & 5 & $59 / 65$ & \multirow{2}{*}{$16 / 30$} \\
\hline W.G. & $417 / 65$ & 114 & $3 / 66$ & \\
\hline Total & $515 / 91$ & 120 & & \\
\hline
\end{tabular}

As measured $F(F=9 / 382)$ is higher than $F=0 / 05$ with d.f. $=5,114$, there is a significant difference between studied groups. According to collected data and considering significant difference between groups, it was concluded that the author's claim on lacking of similarity between groups in respect of the level of happiness is supported. In other words, there is a significant difference between efficacies of two programs in raising happiness in view of the level of the students' depression.

Table 3: the results of ANOVA for state anxiety

\begin{tabular}{|c|c|c|c|c|}
\hline Origin of changes & $\begin{array}{c}\text { Square roots } \\
\Sigma\end{array}$ & d.f. & Mean & F \\
\hline B.G. & $47 / 64$ & 5 & $9 / 53$ & $1 / 77$ \\
\hline W.G. & $613 / 91$ & 114 & $5 / 38$ & \\
\hline Total & $660 / 83$ & 120 & & \\
\hline
\end{tabular}

Table 4: the results of ANOVA for trait anxiety

\begin{tabular}{|c|c|c|c|c|}
\hline Origin of changes & $\begin{array}{c}\text { Square roots } \\
\Sigma\end{array}$ & d.f. & Mean & $F$ \\
\hline B.G. & $51 / 38$ & 5 & $10 / 28$ & \multirow{2}{*}{$1 / 62$} \\
\hline W.G. & $724 / 25$ & 114 & $5 / 38$ & \\
\hline Total & $775 / 63$ & 120 & & \\
\hline
\end{tabular}

As calculated $F s(F=1 / 77 \& 1 / 62)$ are lower than $F=0 / 05$ with d.f. $=5$ and 114 , so there is no significant difference between groups. According to collected data and considering lacking of significant difference between groups, it is concluded that the researcher's hypothesis that groups are not similar in their happiness rate (in view of their level of state and trait anxiety), is supported. In other words, considering the level of state and trait anxiety of groups, there is no difference between two programs in raising happiness.

\section{Discussion and Results}

Results from statistical analyses showed that the Foryce's cognitive- behavioral model of happiness and the Lewinsohn\&Gotlib instruction of social skills are effective in raising the students' happiness. This study results are consistent with those of Fordyce (1983), Lyubomirsky\&Lepper(1999), Abedi (2002), Abedi et al. (2004), 
Lewinsohn\&Gutlib (1995), Lyubomirsky (2001), Ryan \&Deci (2000), Hills \&Argyne(2000), Buss(2000), Gray (1982), Huppke( 2001), Rose(2000), Berry \&Hanse(1996), Lu \&Argyne(1991), Rose \&Mirosky(1989), Philips(1967), Rittner\&Robbin(2002), Phelan(1988), Diener(2000), Myres (2000), Peterson(2000), Beck(1991) and Argyne(1982).

Comparison of group means by Sheffe's test showed that the efficacy of cognitive- behavioral instruction of social skills in raising happiness is higher than Fordyce's model. Effectiveness of these instructions in increasing happiness rate of depressed peoples and their families is also validated in Lewinson\&Gutlib(1995), Hupps\&Lewinson(1995), Varger\& Rutherford(1996), Larson(2000), Kampse\& Ki(2002) and Cheng \&Fornham(2002).

Also, in his study, Argyle (2001) indicated that the extroverts' happiness is due to their better social skills, especially their skill in expressing themselves and cooperation capabilities. Lu \& Argyle (1991) in their research on depressed persons reported that these are reclusive, alone, unsociable, and without appropriate social skills. They believed that effective communication will increase level of extroversion during time. Also, a higher level of happiness in extroverts may be resulted from appropriate social skills and continuation of their activities in society. These findings are consistent with the current study results.

The effectiveness of the Fordyce cognitive- behavioral model of happiness has been verified by different studies. Fordyce (1983) conducted this model on university students and found that it has been successful in raising their happiness. In another study, he proposed that his model is effective in lowering depression and adaptation to it among students. Fordyce (1997) and Lyubomirsky\&Lepper (1999) have, also, verified the above-mentioned results. These findings are consistent with the current study results.

Results of follow-up test showed that increased level of happiness among subjects has been unchanged during time. This is in parallel with the results of other studies such as Dyner (2000), Larson (2000), Lyubomirsky (2001), and lyubomirsky et al. (2005).

Another finding of this study was that there is a significant difference between depression level 3 with the levels 1 and 2. In other words, depressed peoples of level 3 (moderate to acute depression) are more affected by the Fordyce's cognitive- behavioral instructions of happiness and social skills instructions than their level 1 and 2 counterparts.

As said earlier, it seems that depressed peoples, due to their negative experiences, have problem in facing with exposures and information processing. Beck (1978) believes that these patients have different outlines of negative cognitions. These depressing outlines are hidden until one faces with negative stimuli. But, by exposure to enlivening motives, these are recovered gradually (quoted from Toozandejani\&Kamalpour 1995).

Cognitive model supposes that negative assessment of depressed peoples of their function is partly distorted. Compared to independent raters, depressed peoples rate their function more negative, while anxious ones and normal subjects have a relatively correct evaluation of themselves. It appears that the Fordyce's cognitive- behavioral instructions and social skills can decrease negative patterns and, thus, increase happiness.

A more finding proposed that the students' level of happiness is different according to their rate of anxiety. But, difference between groups in post -test and follow up test in respect of level of happiness (according to their state and trait anxiety) was not verified. Trandell\&McNally (1997) in their review on researches, concluded that most of them show biased attention in anxious subjects, but there is little evidence for this in depressed ones. In contrast, there is more evidence that depressed subjects show bias in their memories, but this is not proven for anxious peoples ( MusaviShooshtari 1991). On the other hand, the subjects' level of anxiety was not so high, and this may be a cause of insignificant difference between them.

Overall, researches conducted on happiness have shown that happy and unhappy peoples are different in their thought structure, decision making and motivation. Happy peoples take more advantages of their personal, family, education and social relationships (lyubomirsky et al. 2005). Also, happy peoples consider their surrounding environment interesting and fascinating (Al-e-Yasin 2001). They have more sense of security, make decisions easily, involves in cooperative activities (Myers 2000). According to Ryan \&Deci (2000) positive mental assessments and joy are more lasting in happy peoples. Peterson (2000) stated that happy peoples have a positive attitude about themselves and others. They interpret events as positive and their optimism is realistic.

As cognitive- behavioral instructions of social skills and the Fordyce's model of happiness are effective in raising happiness among students, it must be considered some other major variables. For example, principals and teachers being happy, the schools' structure, holding interesting ceremonies in schools, characters' dimensions, social, cultural and economic states of the students, social supports, social cooperation, organizational and affective climate of school, quality of relationships and etc. are of the major factors influencing the students' happiness. Also, respect for religious values and goals, basic needs of students, making life purposeful and raising spiritual interests in students are of other factors which must be considered in future researches. 


\section{References}

Argail M.(2003). Happiness Psychology, translated by Bahrami F et al., Isfahan.

Argail M.(2003). Happiness Psychology, translated by Gohari M et al., Isfahan.

Darikvandi H.(2002). The study of Enlivening Factors among the Secondary School Students of Isfahan of the viewpoint of principals and educative teachers, M.A. Thesis, Isfahan University.

Abedi M.(2000). efficacy of job consultation according to the social learning, job adaptation theory and the Fordyce's CognitiveBehavioral model of Happiness on lowering job tiredness of consultants working in education office of Isfahan, Ph.D. Dissertation, Humanities Department, AllameTabatabayi university, Tehran.

Abedi M.(2002). the efficacy of the Fordyce's Cognitive- Behavioral model of Happiness on joy, anxiety, depression and social communications of the students of Isfahan University, Summery of Articles,the $4^{\text {th }}$ research week of Isfahan University, Ps 41-47.

Abedi M.(2004). Ahmadi A; \&Nasoohi M, Relationships between Happiness and the School Factors among the High School Students of Mobarake, Isfahan, Psychology quarterly periodical, Islamic Azad University, Khurasgan, Isfahan, Edition 19.

GaryGrathMarnat.(1990). A Guideline to Psychological Assessment, translated by: PashSharifi H; Nikkhoo M, Roshd Pub., Tehran.

MusaviShooshtari M.(1990). Investigation of the Relationships between Affective Climate of Home with the Personal-Social Adaptation and Educational Achievement of Third Grade Students of Secondary Schools of Ahvaz, M.A. thesis, Ahvaz University.

Mahram B.(1993). Normalization of Schpilberger'sstate and trait Anxiety Inventory in Mashhad City, M.A. thesis, Humanities Department, Ferdowsi University, Mashhad.

Al-e-Yasin M.(2001).Happiness and Joy in Schools, Tarbiatjournal,No. 1.

Arglye, M \&\&u,I. (1990). The happiness of extroverts. personality and individual differences, Vol, 11 (1), 1011-1017.

Arglye, M. \& Martin, M. \&Crossland, J. (1989). Happiness as a function of personality and social encounters. In J. P. Forgas\& J. M. Innes (Eds), Recent advance in social psychology: and international perspective (PP. 189 - 203). Amsterdam, the Netherlands: Elsevier science Ltd.

Barlow, J. P. (2002). The measurement of optimism and hope in relation to college student retention and academic success. Ph.D. dissertation, lowa state university, Ames, IA, USA.

Beck, A. T. (1991). Cognitive therapy: A 30-Year retrospective. American psychologist, 46 (4), 368-375.

Berry, D. S., \&Hanse, J. S. (1996). Positive asset, negative affect and social interaction, journal of personality and social psychology, 71 , $796-809$.

Buss, D. (2000). the evolution of happiness. American psychologist, vol. 55 (1), 15 - 23.

Byrd, K. R., lear, D. \&Schwenka, S. (2000). Mysticm as a predictor of subjective well-being, international journal for the psychology of religion, 10 (4) $259-269$.

Cheng, H., \&Fumham, A. (2002). Personality, peer relations, and self - confidence as predictors of happiness nadloneliness, Journal of adolescence, 25 (3), $327-339$.

Diener, E. (2000). Subjective well-being. American psychologist, 55 (1), 34 - 43.

Fordyce, M. (1983). A program to increases happiness. Further studies. Journal of counseling psychology, 30 (4), 483 - 498.

Fordyce, M. (1997). Educating for happiness. Retrieved from http://www.gethappy.net/quebec.htm.

Francis,L. J., Brown, L. B., Lester,D., \&Philipchalk. R. (1998). Happiness as stable extraversion: A cross- cultural examination of the reliability and validity of the Oxford Happiness Inventory among students in the U.K., U.S.A., Australia, and Canada. . personality and individual differences,24 (2),167 - 171.

Gray, J. A. (1982). The neurophysiology of anxiety, oxford, ukiclarendon press.

Hills, P. \& Argyle, M. (2001). Happiness, introversion-extroversion and introverts, personality and individaual differences, 30,595 - 608.

Huppke, R. W. (2001). Study finds community work linked to happiness. http://archivenando time .../ 0, 2107,500045722 - 500698037 $503784788-0,00 \mathrm{html}$ ? Printe.

Kamps. D.M., \& Kay. P. (2002). Preventing problems through social instruction. In B. Algozzine\& P. Kay (Eds), Preventing problems behaviors: a handbook of successful prevention strategies (pp.57-84). Thousand Oaks, CA. USA: Corwin press.

Larson, R. W. (2000). Toward a psychology of positive youth development. American psychologist, 55 (1), 170-183.

Lewinsohn, P. M., \&Gotlib, I. H. (1995). Behavioral theory and treatment of depression. In E. E. Beckham \& W. R. Leber (Eds), Handbook of depression (2nd Ed. pp, 352-357). New York. NY, USA. Guilford press.

Lu, L. \& Argyle, M. (1991). Happiness and cooperation. Personality and individual differences, 12 (10). Pp, 1019-1030.

Lu, L., \& Argyle, M. (1991). Happiness and cooperation. Personality and individual differences. 12 (10). 1019-1030.

Lyubomirsky, S. (2001). Why are some people happier than others? The role cognitive and motivational processes in well-being. American psychologist. 56 (3), 239 - 249.

Lyubomirsky, S. (2001). Why are some people happier than others? Psychologist, vol. 56 (3), 239 - 429.

Lyubomirsky, S., \&Lepper, H. S. (1999). a measure of subjective happiness: preliminary reliability and construct validation. Social indicators research., 46 (2), 137 - 155.

Lyubomirsky, S., sheldon, K. M., \&Schkade, D. (2005). Pursuing happiness: the architecture of sustainable change. The general psychology. 9 (2), 111 - 131.

Meyer, D. (2000). The friends, funds, and faith of happy people. American psychologist. 55 (1), 56 - 67.

Myers, D. G. (2002). Happy \& healthy. <http://abclocal. g. com/68-wls/news/012802-hs-happy healthy. html.

Peterson, C. (2000). The future of optimism. American psychologist. 55 (1), 44 - 55. 
Phelan, R. J. J. (1998). The relationship between student and teacher perception of the organization climate of their school. http://www.lib. umi.com/dissertations/ preview.

Philips, D. L. (1967). Social participation and happiness, The American journal of sociology, 72. (5). pp, 749-488.

Raterink, G. V. (2002). Why Do Some Students Succeed? American school board journal, V, 189 n2p3 Feb 2002, <ERIC\#: EJ640874.

Reiss, S. (2001). Secrets of happiness. Psychology today, 34, pp. 50 - 55.

Rittner - heir, robbin, M. (2002). Color and light in learning, School planning and management, V,41 n2, p57 - 58, 60 - 61.

Rose, C. E., \&Mirowsky, J. (1989). Explaining the social patterns of depression: control and problem-solving or support and talking, journal of health and social behavior, 30, $206-219$.

Rose, R. (2000). How much does social capital add to individual health? A Survey Study of Russian Social Science \& medicine, 51 (9). $1421-1435$.

Ryan, R. M., \&Deci, E. L. (2000). Self-determination therapy and the facilitation of intrinsic motivation, social development and wellbeing, American psychologist, 55 (1), 68 - 78.

Thompson, Sh. (2003). Color in Education. School planning and management 42, n12, p30 - 32.

Trandel, D.V., \& McNally, R.J. (1997). Perception of threat cues in post-traumatic stress disorder semantic processing without awareness? Behave. Res. The, 6, $469-476$.

Warger, C. L. \& Rutherford, R. (1996). Social skills instruction. A collaborative approach. Ann Arbor. MI, USA: Foundation for exceptional innovations. 